VARIA 


\section{O "estilo subjetivo" virgiliano e a tradução portuguesa do mito de Orfeu nas Geórgicas de Antônio Feliciano de Castilho}

Matheus Trevizan

Universidade Federal de Minas Gerais

\section{a) Introdução e apresentação do instrumental analítico}

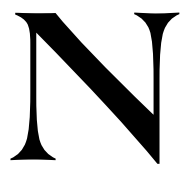

uma clássica contribuição para o conhecimento da arte de Virgílio, o crítico norte-americano Brooks Otis propôs, na década de sessenta do século passado, a distinção entre "estilo objetivo" e "estilo subjetivo" nos versos deste poeta antigo. ${ }^{1}$ Segundo ele, então, corresponderia ao primeiro tipo de organização dos recursos discursivo-formais da poesia virgiliana uma forma de narrar à maneira "distanciada" (concretamente imagética, desprovida de grandes "afloramentos" reflexivos da parte do narrador, evocativa do tom "límpido" da dicção épica homérica...), característica de passagens em que, apenas, intenta-se dar vazão ao minimamente esperado de quem conta uma história, isto é, ao puro concatenar de eventos em série.

O "estilo subjetivo", por sua vez, característico de aportes virgilianos no cotejo com os grandes épicos anteriores (sobretudo Homero e Apolônio de Rodes, autor das Argonáuticas), definir-se-ia justamente por indiciar ao público, através de certos mecanismos linguísticos "catalogáveis", o

${ }^{1}$ OTIS, 1995, p. 41-96 (a primeira edição de Virgil: a study in civilized poetry, no entanto, data de 1963). 
decisivo "envolvimento" do narrador com o narrado, como se, aqui, de fato transparecessem até as "emoções" de Virgílio. Entre os recursos passíveis de despertarem tal efeito na leitura, citamos, a título de esclarecimento, ${ }^{2}$ a farta presença de verbos (ou outras expressōes) de sentimento, a deliberada exploração de efeitos rítmicos e sonoros, com vistas a refletirem-se no plano dos sentidos, a sintaxe que se constrói amiúde reflexiva e interrompendo o curso das ações, o emprego do discurso indireto livre, a fuga à excessiva complexidade dos símiles e o nexo cabível, desses últimos, com estados de espírito internos às personagens.

Uma das passagens da Eneida citadas por Otis ajudar-nos-ia a demonstrar na prática em que consiste o segundo modo de elaboração estilística citado acima: em canto V 315-342 desse épico, assim, quando assistimos às disputas entre vários moços do povo de Eneias na ocasiáo dos jogos fúnebres de Anquises, o pai do herói, oferece-nos o ensejo para divisarmos, via análises do crítico norte-americano, ${ }^{3}$ lampejos da "subjetividade" construtiva de Virgílio.

Em primeiro lugar, observa ele, enquanto abundam vários epítetos e patronímicos típicos da épica helênica num trecho homérico que compara (Ilíada XXIII 757-783), Virgílio, quando descreve seus heróis, designa Niso, um dos competidores, por infelix ("pobre"), como se estivesse a compadecer-se da desvantagem de quem pareceu pôr sob destaque "afetivo"; em seguida, no contraste com o que Otis interpreta, em Homero, como maior "neutralidade" expressiva, ${ }^{4}$ o poeta romano multiplicou nessas linhas alguns verbos atinentes às sensações dos próprios corredores (corripiunt spatia - "tomam seu lugar", emicat - "irrompe", uolat - "voa"), além de adjetivos ou expressões "qualificativas" do tipo de infelix (visto há

${ }^{2}$ OTIS, 1995, p. 61-62.

${ }^{3}$ OTIS, 1995, p. 41-61.

${ }^{4}$ AUERBACH, 2002, p. 1-20 (sobre a imediatez representativa do estilo homérico no contraste com a "abissal" narrativa do dito "eloísta" do Velho Testamento). 
pouco), non ille oblitus amorum e iuuenis uictor auans ("sem esquecer-se ele dos amores", "moço vencedor a ovacionar"); o verso 324, por sua vez, com a sistemática alternância entre os pés dátilos e espondeus ao se tratar do avanço de Diores, a repetição de calcem/ calce ("calcanhar") e a existência de duas "dinamizadoras" cesuras métricas, deixa-o entrever a mimetização da fortuita velocidade dessa personagem; nos versos 325-326, em que se nota a presença de um período hipotético eventual, toda a estrutura se coloca como "comentário" estranho ao desenrolar da corrida (mas afim ao destaque da sanha competitiva de Diores!); os curtíssimos símiles utilizados por Virgílio nesse episódio (versos 317/ 329-330), enfim, furtam-se à tradição homérica de conceder-lhes significativo destaque visual e, postos em contextos de esforços (baldados ou não) dos atletas, "refletem-lhes" as experiências durante o certame.

Em que pese às críticas possíveis aos procedimentos analíticos de Otis, relativas, talvez, a alguma dose de arbitrariedade na explicação dos efeitos desencadeados pelos recursos de língua e estilo acima arrolados (chamamos a atenção, sobretudo, para a eventual fraqueza dos traços rítmicos citados em sua face "evocativa" da vantagem de Diores na corrida), trata-se, em primeiro lugar, de aspectos conjunta e coerentemente presentes em muitos trechos lidos pelo crítico. Além disso, como as colocações do autor encontram ressonâncias também nas palavras de outros abalizados estudiosos de Virgílió e os traços do "estilo subjetivo" correspondem, em parte, a pontos perceptíveis na própria materialidade do emprego vocabular ou das frases, tomamo-lo por parâmetro válido das peculiaridades estilísticas virgilianas.

Assim, no posterior cotejo do original latino em questão (um trecho do livro IV das Geórgicas - versos 453-527 -, identificável com o relato do deus marinho Proteu e, de resto, previamente analisado por Otis segundo o instrumental descrito) com seu correspondente português do século XIX, intentaremos delinear até que ponto a arte tradutória de Castilho logrou manter-se afinada com tais modulações da arte de Virgílio.

${ }^{5}$ HEINZE, 2004, p. 295-297. 


\section{b) O mito de Orfeu nas Geórgicas: inserção e traços estilísticos}

Justo ao fecho de suas Geórgicas, poema didático em quatro livros dedicado ao tema comum dos trabalhos rurais (especificamente, no de nosso interesse, ao da apicultura), Virgílio votou-se com esmero a dotálas de uma peça "autônoma" complexa: referimo-nos ao assim chamado epýllion de Orfeu e Aristeu. De acordo com tendências compositivas perceptíveis desde a época helenística da literatura grega, ${ }^{6}$ trata-se de uma forma sempre dedicada a relatos mitológicos, donde lhe vem a afinidade com a épica, composta em hexâmetros datílicos (o mesmo metro da epopeia grega desde Homero e da latina desde os Annales de Ênio) e a conter, numa só peça/ poema, o "encastoamento" de uma história em outra: assim, no exquisitus poema 64 de Catulo, em que nos são contadas em primeiro plano as bodas de Peleu e Tétis, ocorre a momentânea interrupção dos eventos expostos de imediato para que se nos mostre, no intervalo dos versos 50-264, o rapto e abandono de Ariadne por Teseu. ${ }^{7}$

Adaptado nas Geórgicas a esse modelo, tão ao gosto de poéticas a que, decisivamente, se vinculara desde as Bucólicas, ${ }^{8}$ Virgílio fez do mito órfico o "quadro" narrativo "emoldurado" pela história de Aristeu. Esse, lendário apicultor do imaginário grego, era filho da ninfa aquática Cirene e do próprio deus Apolo. Espécie de contraponto, na economia interna das Geórgicas, do modo de vida contemplativo de Orfeu (pois que se dedicava, como convinha a um "herói” de poesia didática agrária, aos labores quotidianos de obter o mel de suas abelhas), viu-se um dia, no entanto, diante de embaraçosas dificuldades práticas: morrendo-lhe todos os enxames de forma misteriosa, foi, assim, ter com a mãe em seus domínios fluviais a fim de aconselhar-se.

\footnotetext{
${ }^{6}$ CATULO, 1996, p. 31-33.

${ }^{7}$ CATULO, 1996, p. 120-133.

${ }^{8}$ OTIS, 1995, p. 101 ss.
} 
Embora Cirene, pelo relato de Virgílio, não tenha sabido desvendar as causas do mal a afligir Aristeu, recomendou-lhe a captura de Proteu, divindade marítima dotada da onisciência, para que pudesse, enfim, encontrar as respostas desejadas. O relato divino de Proteu, a custo tomado numa rede de pesca por Aristeu, corresponde ao que lemos nas Geórgicas como o mito órfico.

Basicamente, a desgraça de Aristeu produziu-se aqui por uma maldição dos Manes de Orfeu e Eurídice, já que, sem o desejar, acabara indiretamente causando a morte da moça: em fuga à violência do estranho, ela pisara por acidente numa serpente letal às margens de um rio. Morta a esposa, um inconsolável Orfeu comovera com seu canto os deuses dos Infernos e, vivo, aí penetrara para resgatá-la; sem, no entanto, poder cumprir as condições da rainha Perséfone, que lhe vetara olhar para Eurídice até a total saída de ambos à superfície, ele falhou em seus intentos e perdeu-a para sempre. Como resultado do desespero, Orfeu, ao final, enlouqueceu e foi esquartejado pelas Bacantes trácias.

O desfecho do epýllion, com o retorno à "moldura" dos conflitos produtivos de Aristeu, vincula-se aos ensinamentos da técnica da bougonía pela ninfa ao filho: segundo processo descrito nas Geórgicas, essa era a prática de sufocar um novilho sob condiçôes especiais a fim de que, de seu corpo decomposto, "brotassem" os novos enxames de abelhas. Seguindo as instruções de Cirene, por sinal, Aristeu acaba por livrar-se com sucesso dos contratempos pouco antes de as Geórgicas terminarem. ${ }^{9}$

Pelo dito, vê-se que o epýllion em questão encontra uma justificativa etiológica para adentrar a trama do livro derradeiro das Geórgicas: por esse motivo, mais uma vez, encontramo-nos de novo no universo da poética alexandrina, pois, tendo os poetas helênicos dessa tendência sido muito eruditos, ${ }^{10}$ frequentemente lhes integrou as obras o gosto de explicar as origens (t'aitia) de práticas e costumes recorrendo a saberes recônditos,

\footnotetext{
${ }^{9}$ WILKINSON, 1997, p. 120.

${ }^{10}$ LEGRAND, 1924, p. 52-61.
} 
ou, até carregados de exotismo, como é o caso dos implicados na técnica geradora da bougonía.

Importam-nos mais, no entanto, outros traços da tessitura poética do trecho mítico que, especificamente, destacamos do epýllion para a presente análise. Ao rejeitarem modelos genéricos em larga escala para reduzi-los assim, os autores helenísticos não renunciavam, entretanto, a cultivar ao extremo os requintes da forma. Corresponde, por sinal, a um dito célebre de Calímaco cirenaico, um dos maiores expoentes dessa "escola", proferir que "um grande livro se equipara a um grande mal". ${ }^{11}$ Com isso, entendia-se que a tônica compositiva então em voga era, de preferência, "limar" poucos versos a fazer longuíssimos textos (sobretudo épicos ou históricos, gêneros tidos por "sérios") em tom gradiloquente; por outro lado, pela redução da escala compositiva das obras, visava-se não só a "encurtar" os textos em esmerada operação de escrita, mas, além disso, à focalização da vida sob aspectos em geral negligenciados em esferas compositivas mais solenes. Referimo-nos, aqui, aos planos experienciais dos afetos (ou desafetos) dos autores, às suas vivências amorosas ${ }^{12}$ e do próprio processo de fazer poesia para a apreciação num círculo restrito de connaisseurs...

Certas colocações de Otis, quando analisa todo o epýllion de Orfeu e Aristeu, por sinal, dão-nos a ver que Virgílio parece bem mais alexandrino ao compor o centro dessa peça do que os extremos, ${ }^{13}$ ou seja, as partes inicial e derradeira, diretamente referentes aos eventos que dizem respeito à última personagem. Segundo comprovam, à maneira do que antes fizemos ver ao reproduzir-lhe as análises concernentes a Eneida V 315342 , inclusive certas comparações com o estilo homérico, enquanto as partes do epýllion vinculadas a Aristeu (e aos tons mais "solares" de eventos que descrevem até preocupações comezinhas de um apicultor) apresentam

${ }^{11}$ CATULO, 1996, p. 31.

${ }^{12}$ LEGRAND, 1924, p. 61ss.

${ }^{13}$ OTIS, 1995, p. 200. 
afinidades com o modelo expressivo épico e, nos termos de Otis, o "estilo objetivo", a parte do meio, justamente identificada com o mito órfico, constrói-se em escala intimista e trabalhada ao extremo. ${ }^{14}$ Ademais, como a trama toda está centrada no personalíssimo conflito do poeta de amor que é Orfeu, a narrativa então se reveste de colorações oníricas e assume características francamente condizentes com as do chamado "estilo subjetivo": tudo se dá, nessa passagem, como se Virgílio, também ele poeta, e, dizem-nos os críticos, "misericordioso" dos vencidos pelas agruras da vida, ${ }^{15}$ viesse a projetar a própria sensibilidade sobre eventos descritos de maneira "engajada".

$\mathrm{O}$ arranjo mesmo dos eventos no relato do mito de Orfeu, assim, já significa muito no tocante aos supostos posicionamentos de Virgílio: Otis demonstra, de maneira dificilmente refutável, como a dispositio encontrada na passagem aponta, com simetria, para uma espécie de colocação em destaque do que chama de "triunfo do canto humano", ou seja, do próprio fazer poético de Orfeu enamorado, vencedor até da morte num primeiro momento (versos 471-484); de um modo gradativamente descentrado, temos, então, antes e depois disso, a "desumanidade do Hades" (versos 467-470) e a segunda separação de Orfeu e Eurídice (versos 485-507); em seguida, na mesma sequência, o lamento pela primeira morte de Eurídice (versos 460-466) e pela segunda (versos 507-515); derradeiramente, a morte da esposa (versos 453-459), seguida pela morte do próprio Orfeu (versos 516-527). ${ }^{16}$

E, no nível do agenciamento dos recursos linguístico-discursivos do "estilo subjetivo", põem-se sob luz especial pontos como os seguintes: ${ }^{17}$ no

${ }^{14}$ OTIS, 1995, p. 201ss.

15 O'HARA, 1997, p. 253-254.

16 OTIS, 1995, p. 199.

17 OTIS, 1995, p. 200-203 (tal sequência de páginas refere-se, a seguir, a todos os recursos do estilo subjetivo virgiliano elencados por Otis ao tratar do relato do mito órfico das Geórgicas e por nós citados, até a introdução do tema do discurso-indireto livre neste texto). 
verso 457, o pronome pessoal te é endereçado de Proteu a Aristeu, que o ouve para informar-se das causas da perda de suas abelhas; nos versos 465466, por outro lado, de forma muito enfática (gerando repetiçōes, anáfora, aliterações e assonâncias!), o mesmo te se volta para ninguém menos que Eurídice morta: te, dulcis coniunx, te solo in litore secum, / te, ueniente die, te decedente canebat. ${ }^{18}$ Nesse caso, a voz do narrador (o deus Proteu) como que se confunde com a de Orfeu enamorado, pois, sabemos, quem não desistia de chamar obsessivo essa mulher era o próprio marido...

De forma muito característica, acrescentamos com Otis, a adjetivação da passagem aponta com frequencia para afastamentos da mera frieza descritiva: Orfeu é miserabilis (“infeliz", verso 454), Eurídice é dulcis (“doce", verso 465), Plutão é rex tremendus ("rei tremendo", verso 469), os heróis mortos, no Hades, são magnanimi (“abnegados”, verso 476), as paragens do Cocito infernal são palus inamabilis ("palude odioso", verso 479), o rei do Tártaro, de novo, é immitis tyrannus ("tirano duro", verso 492)... Sem termos finalizado o "catálogo" de toda a expressiva adjetivação virgiliana ao desenvolver essa história, fazemos, no entanto, atentar para como ela é indicadora do gesto narrativo de "pôr-se no lugar do outro" (Orfeu), cujas amargas vicissitudes nos vão, aos poucos, sendo desveladas sob uma ótica de todo empática diante de seus sofrimentos.

Embora esse crítico não tenha comentado a mesma passagem assim, destacamos, nos versos 473-474, em que se tem um pequeno símile, a vigência de um efeito antes descrito por ele para tais figuras de linguagem no "estilo subjetivo". ${ }^{19}$ De fato, nesse contexto, o símile referido, embora breve, evoca vivamente a grande quantidade de almas divisadas pelo próprio Orfeu [quem mais, senão ele, teve o estranho "privilégio" de testemunhar em vida e com seus olhos as sombrias paragens infernais? quem mais, segundo nos é informado por Proteu nos versos 507-509, depois cantou por sete meses suas dores e "essas coisas" ( haec, verso 509)?] quando baixou

18 "A ti, doce esposa, a ti sozinho consigo na praia,/ a ti, vindo o dia, a ti, ao findar, cantava”. (tradução minha)

${ }^{19}$ OTIS, 1995, p. 59. 
ao Hades para buscar a esposa: at cantu commotae Erebi de sedibus imis/ umbrae ibant tenues simulacraque luce carentum/ quam multa in foliis auium se milia condunt/Vesper ubi aut hibernus agit de montibus imber. ${ }^{20}$

$\mathrm{Na}$ sequência, segundo lembrado também por Otis, não só o número, mas a própria qualidade dos Manes que acodem hipnotizados pelo canto de Orfeu [pois que são, patética e universalmente, "matronas" (matres, verso 475), "varões" (uiri, mesmo verso), "heróis generosos" (magnanimum heroum, verso 476), "meninos" (pueri, mesmo verso), "moças solteiras" (innuptae puellae, mesmo verso), e "jovens depostos sobre piras diante da face dos pais" (impositique rogis iunenes ante ora parentum, verso 477)] concedeà imagem das sombras de além-túmulo tons de "envolvimento" do narrador, dadas as palavras por ele escolhidas, combinadas e sequenciadas para expressar-se...

Embora muito mais se pudesse dizer aqui sobre a delicada tessitura poética (e subjetiva) do episódio de Orfeu e Eurídice, preferimos, para o restante, remeter o leitor à obra do mesmo Otis, ${ }^{21}$ não, contudo, antes de finalizarmos com a menção a uma última passagem de expressivo afloramento do discurso indireto-livre na fala do narrador virgiliano. ${ }^{22}$ São meros dois versos (504-505), todavia carregados de especial interesse para os propósitos analíticos que aqui nos dizem respeito: quid faceret? quo se rapta bis coninge ferret?l quo fletu Manis, quae numina uoce moueret? $?^{23}$

Segundo recorrente explicação dessa modalidade narrativa, tratase de uma espécie de forma "mista" de contar, na medida em que, embora se reproduzam com grande fidelidade as palavras da personagem, isso não

20 "Mas, movidas pelo canto, das profundezas do Érebo/ saíam as sombras sutis e os fantasmas dos sem-luz/ quantos são os milhares de aves a ocultar-se nas folhas/ quando Vésper ou a chuva invernal as toca dos montes”. (tradução minha) ${ }^{21}$ Cf. supra nota 17 e OTIS, 1995, p. 203ss.

22 OTIS, 1995, p. 204.

23 "Que faria? Aonde iria, tirada duas vezes a mulher?/ Com que choro os Manes, que Numes com sua voz comoveria?”. (tradução minha) 
se faz diretamente (apenas citando-as "tal como foram ditas"), mas recorrendo ao artifício de percorrer-lhe o fio da consciência por via indireta. Apesar disso, suprimindo-se as marcas linguísticas de inequívoca presença do narrador ("ela disse", "o comandante então gritou”...), reforçase o fato de o discurso indireto livre aproximar-se muito da expressão do próprio ser "retratado"... ${ }^{24}$

Quando, assim, Proteu (ou, como se quiser, no verdadeiro jogo de bonecas russas em que se constitui aqui a ficção, Virgílio) se pronuncia pelo modo em questão, como que provisoriamente "vacilamos" sobre quem teria proferido aquelas palavras: trata-se, enfim, de mais um trecho narrativo vazado pelo narrador ou, fato sem outros paralelos na passagem em vista, da "vinda à tona" dos ditos de Orfeu? Nem uma coisa nem outra, pois que, prevenidos pela palavra dos críticos (e por nossa própria sensibilidade), nela entrevemos a simultânea justaposição de modos expressivos extra e intracentrados...

Por fim, o que se tem a ganhar com isso patenteia-se a todos quando nos lembramos de que a invariável tônica do "estilo subjetivo" virgiliano, segundo Otis, correspondia a qualquer "identificação" do narrador com o narrado, ${ }^{25} \mathrm{ou}$, ainda, com os eventos ou personagens de que tratava empático.

\section{c) A tradução portuguesa do mito de Orfeu nas Geórgicas de Antônio Feliciano de Castilho}

De início, a tradução portuguesa do mito órfico das Geórgicas revelase-nos, aparentemente, bem mais prolixa do que a virgiliana: confrontados com cento e três versos desta feita (quando havia apenas setenta e cinco no intervalo latino dado! - IV 453-527), quase nos esquecemos de relativizar tais cifras por um lado diverso. Na verdade, o hexâmetro datílico,

${ }^{24}$ LODGE, 1996, p. 15-16.

${ }^{25}$ OTIS, 1995, p. 49ss. 
metro aqui empregado por Virgílio, é, sempre, mais longo do que os alexandrinos portugueses: no mínimo, conta com treze sílabas e, no máximo, com dezessete, ${ }^{26}$ ultrapassando seguro o maior dos versos consagradamente "nobres" na tradição poética de nosso idioma. ${ }^{27}$

Sem vãs tentativas de "contabilizar" os estilos dos poetas com base na mera frieza numérica, cogitamos que, em latim, talvez caiba semelhante quantidade de palavras em menos versos... mais longos. Além disso, quando se compara o caráter sintético da língua latina com o analítico da portuguesa, naturalmente se vê que buscar aqui uma concisão tão habitual quanto lá poderia resultar falseador da verdadeira índole expressiva vernacular.

Mas, no contraste com a relativa liberdade construtiva do ritmo nos hexâmetros em latim, a estrutura "fixa" dos alexandrinos, ${ }^{28}$ de fato, ofereceu a Castilho menores chances de variar. Corresponde, pois, a uma tentativa de fazer-se sonoramente rico o emprego, pelo poeta português, de rimas muito distintas ao final de cada par de versos subsequentes: com isso, destacamos, ele decerto dotou sua versão de uma tessitura sonora alheia à plena monotonia.

No caso das passagens já citadas ao ilustrarmos o "estilo subjetivo" virgiliano, o direto cotejo latim/ português é o que nos assegurará agora os meios de depararmos as efetivas soluções do tradutor luso para recriar o relato de Proteu. Remetendo-nos ao dito antes sobre o "eco" do

${ }^{26}$ Tal variação se deve porque o esquema do hexâmetro datílico admite, nos quatro primeiros pés métricos, a livre alternância entre dátilos e espondeus, considerada a equivalência de uma sílaba longa para cada duas breves na contagem. ${ }^{27}$ GOLDSTEIN, 1986, p. 32-33.

${ }^{28}$ Os alexandrinos (versos de doze sílabas) em geral são acentuados ao fim do primeiro e do segundo hemistíquio (como nos exemplifica este primeiro verso do "Spleen" - Les fleurs du mal - de Charles Baudelaire: J'ai plus de souvenirs/ que si j'avais mille ans), ou, menos perfeitamente, na quarta, oitava e décima segunda sílaba. 
chamamento a Eurídice nos versos 465-466 do original, transcrevemos abaixo o correspondente trecho de Castilho:

(...). Por ti, consorte amada,

por ti, consigo a sós, na praia descampada,

por ti, raiando a luz, por ti, quando atro manto

a noite desdobrava, enchia de ais o canto.

A reiteração, por quatro vezes seguidas, do pronome pessoal oblíquo em português indicia-nos o rigor tradutório ao verter do latim, pois, em Virgílio, havia-o por idêntico número de vezes; em si mesmo considerada, por sinal, essa repetição é evocativa da musicalidade dos versos virgilianos, pois de novo gera ênfase "subjetiva" pela via das aliterações e assonâncias. Para a plena apreciação desse efeito, é importante notar em Castilho a "contaminação" do entorno pelos queixumes de Orfeu: já na primeira linha transcrita há pouco, a pronúncia esperada do "e" átono final indubitavelmente aproxima o "fecho" da palavra "consorte" do próprio pronome posto em destaque nesses versos; mutatis mutandis, ocorre na última linha um efeito semelhante ao ouvirmos o termo "noite", e a reiteração adicional da vogal "i" (contando seis ocorrências alheias a "ti" e aos finais de palavra aludidos) e de " $\mathrm{t}$ " (por três vezes alheias a isso, todavia reforçadas por se encontrarem os sons num contexto de rima ou de sua proximidade) não deixa de ter suas consequências para conjugar habilmente a forma e os sentidos.

O obsessivo "espelhamento" do pesar de Orfeu não só na fala do narrador (o que importa de imediato à problemática do "estilo subjetivo"), mas, ainda, sobre a natureza mesma (pois, em "praia descampada", "raiando a luz" e "quando atro manto/ a noite desdobrava", como vimos, subsiste algo de Eurídice), remete-nos a um ponto destacado por Otis quando tratou do pranto "universal" diante da primeira morte dessa mulher. ${ }^{29}$ Também a intensidade e a extensão do lamento (contrastada

${ }^{29}$ OTIS, 1995, p. 201-202. 
com a subsequente solidão de Orfeu), observava o crítico norte-americano sobre os versos 460-463 de Virgílio, correspondia a um modo de o poeta reforçar, no "comprometido" relato de Proteu, o patético do enredo: cabe, pela ficção engendrada nas Geórgicas, a esse deus e a ninguém mais a seleção dos recursos discursivos cabíveis para impressionar Aristeu e torná-lo dolorosamente ciente do alcance de sua falha para com o casal em pauta. Isso significa que, tendo citado o "coro igual das Dríades" (verso 460), os "montes" (verso 461), as "cidades rodopeias" (mesmo verso), os "altos Pangeus" (verso 462), a "terra belicosa de Reso" (mesmo verso), os "getas" (verso 463), o "Hebro" (mesmo verso) e "Orítia ática" (mesmo verso), Virgílio fê-lo "mostrar" enfático quão sentida a morte de Eurídice foi por todos (e não, apenas, noticiá-la sumário...).

Ora, assim como nessa passagem, antes destacada por Otis por sua força expressiva, o trecho de que nos ocupamos em Castilho (ou, já, sua “matriz" virgiliana) "dramatiza” e agrava a perda de Eurídice ao torná-la, se não tanto ululantemente pranteada, algo amiúde evocado - além de por Orfeu só - até pelos elementos inanimados da paisagem... Curiosamente, ainda, dois desses elementos (a "praia" e o "raiar") ecoam a interjeição de dor ("ais") que se diz, no último verso transcrito acima, encher o canto do próprio Orfeu... ${ }^{30}$

$\mathrm{Na}$ questão dos adjetivos (ou expressões qualificativas em geral) de que se vale Antônio Feliciano de Castilho ao indiciar a emotividade do narrador, também encontramos bons parâmetros para divisar a tessitura estilística dos versos portugueses por ele compostos. Assim, confrontandoo em parte com os usos virgilianos neste quesito, observamos o emprego de "misérrimo Orfeu" para verter o latim miserabilis Orpheus (verso 454), de "consorte amada" por dulcis coniunx (verso 465), de "o atroz que empunha o cetro/ do império morto" por rex tremendus (verso 469), de meros "heróis" por magnanimi heroes (verso 476), de "(do Cocito)

30 Trata-se, aqui, de um funcionamento de tipo "onomatopaico" (GOLDSTEIN, 1986, p. 54). 
horrífico" por palus inamabilis (verso 479), de "cru tirano" por immitis tyrannus (verso 492)...

Ressalva feita à quarta ocorrência citada (com, sem mais, o deliberado apagamento do adjetivo virgiliano correspondente!), todas as demais mantêm a funcionalidade dos qualificadores originais; em "misérrimo", pois, pelo uso do superlativo em nosso idioma, chega-se mesmo a intensificar o efeito do mais banal termo latino miserabilis (literalmente, "digno de compaixão"); na correspondência de "amada" a dulcis, embora se tenha produzido certo apagamento de traços semânticos presentes em Virgílio, introduziram-se outros, com o reforço, aqui, de um estado decorrente dos atributos de Eurídice e, lá, precisamente, de uma característica passível de despertá-lo: por isso, então, entendemos Antônio Feliciano de Castilho algo interpretativo nesta sua opção; em "atroz" por tremendus, parece, fica sempre assegurada a característica de ser bem temível Plutão (ou Dite), rei dos Infernos na mitologia antiga: embora o termo latino em questão evoque mais concretamente, pela proximidade morfossemântica, um efeito psíquico do medo (pois que se vincula ao próprio verbo latino tremere - "tremer"), "atroz" é intenso e da linguagem culta em português e, ${ }^{31}$ assim, apropriado para aludir ao caráter assustador de uma personagem tão em destaque na hierarquia dos deuses inferiores quanto essa; além disso, no plano sonoro, "atroz" e tremendus encontramse indelevelmente afins; a tradução de inamabilis por "horrífico", em seguida, parece-nos especialmente feliz no contexto, pois se trata, aqui, de (des)qualificar as tétricas paragens do Hades (frias, úmidas, escuras, lúgubres, claustrofobicamente constritoras das almas dos mortos, tristes...) recorrendo a um adjetivo inserido numa família de palavras de todo negativas ${ }^{32}$ e, ainda, "auxiliado" por certa aspereza sonora inaudita no

${ }^{31}$ RODRIGUES LAPA, 1973, p. 107. (Sobre o especial efeito de adjetivos cultos sobre substantivos "vulgares", como no banal "brinquedos de criança" contraposto a "brinquedos pueris").

32 "Horror", "horrendo", "horroroso"... 
vocábulo original (do "duplo" "r");33 esse, pelo contrário, embora também atinente a significados depreciativos ("não-amável”, "odioso”, "detestável”...), soava, na língua latina, indequadamente brando aos ouvidos, nasalisado, a conter um par de bilabiais ("m" e "b"), uma fluida "líquida" identificada com o "l"... Por fim, "cru tirano", com suas feições mais concretas (evocativas não só de um estado passível de despertar-nos reminiscências de olfato e gustativas, mas, ainda, da rubra imagem do "cruor"), ${ }^{34}$ parecenos, diante do bem-soante latino inmitis - atente-se, sobretudo, para a doçura do encontro das nasais e a harmonizadora assonância em "i”! superior no quesito de uma expressividade do mal...

Em que pese, aqui, ao fato de Antônio Feliciano de Castilho ter "diluído" uma vez a concisão latina em notória "prolixidade" (note-se, a propósito disso, a terceira ocorrência, que desdobra meras duas palavras em nove!), no todo soube fazer-se equilibrado e eficaz ao traduzir. Por outro lado, esse pequeno "deslize" (bem como o de não ter, à diferença de Virgílio, adjetivado seus "heróis") se encontra "compensado", por assim dizer, quando lhe lembramos a boa escolha dos adjetivos "horrífico" e "cru".

O primeiro símile empregado por Virgílio nessa seção específica das Geórgicas recebeu, nas mãos de Castilho, o tratamento seguinte:

as sombras dos sem-luz subiam-se aos milhares;

quais pássaros num souto ao fim da tarde, ou quando

dos montes Austro hiberno os veio profligando.

Mantendo-se na tradução os mesmos efeitos “empáticos” de exprimir a experiência visual do próprio Orfeu, chamamos, no entanto, a atenção para algumas peculiaridades construtivas da figura em português. De início, por uma característica inerente à própria opção tradutória de Castilho, a rima ao término do par de versos que a constitui confere-lhe

33 RODRIGUES LAPA, 1973, p. 14-15. (Sobre impressões causadas por certas palavras portuguesas - "só", "garota", "rainha", "menina”... -, inclusive por sua sonoridade, sobre os ouvintes).

${ }^{34}$ RODRIGUES LAPA, 1973, p. 13. (Sobre o efeito semântico da "sinestesia"). 
significativa unidade formal; também o fazem as aliterações em nasais e em "s". Ainda, embora a maior concretude da expressão latina tenha aqui cedido a termos mais abstratos (compare-se in foliis - "nas folhas", verso 473 - com "num souto" e Vesper - "Estrela da tarde", verso 474 - com "ao fim da tarde"), mantiveram-se as principais imagens e a exata extensão do original pela justa via dos acertos na sensibilidade.

No desdobramento qualitativo (não quantas, mas quais eram os tipos de almas divisadas por Orfeu quando baixou vivo aos reinos de Dite?) desse ponto do mito órfico nas Geórgicas, por sua vez, opera-se agora segundo a marca da concisão. Em Virgílio, o trecho correspondente contava três versos (475-477), diante, apenas, dos dois de Castilho:

donas, varōes, heróis, meninos, virgens, quanto mancebo foi à pira ante seus pais em pranto;

O que explica a sensível diminuição nesse rol, nota-se bem ao comparar, é sua estrutura mais despojada de uma "lista" 35 de admitidos ao mundo dos mortos. Nesse sentido, cessa aqui algo da dramaticidade virgiliana (e, como não dizer, da força do "estilo subjetivo" na narração) para, apenas, que se enfileirem as categorias de personagens divisadas pelo mítico vate no além-túmulo. Mesmo o segundo verso de Castilho demonstra a opção por recursos expressivos que, embora capazes de afastarnos a impressão da mera "listagem" constituída pelo anterior, encontramse, a bem dizer, divergentes da verdadeira arte de Virgílio: ali, para grande concretude física, não se mencionava qualquer "choro" dos pais dos filhos mortos, só as próprias piras onde foram depostos (impositi, verso 477) a consumir diante da face deles...

Como último recurso comentado quando tratamos, através das críticas de Otis, do "subjetivismo" no mito órfico das Geórgicas, fazemos, agora, menção ao correspondente português da passagem em estilo

\footnotetext{
${ }^{35}$ Sob outro ponto de vista, a fria listagem dos tipos de almas poderia, nessa passagem, resultar em si expressiva por "indiciar" que, brutal, a morte nada vê ou poupa quando se trata de aumentar o número de suas presas...
} 
indireto-livre em Virgílio. Neste ponto, Castilho, com um maior "peso" do narrador nos dizeres, enfraquece o potencial semântico vertendo:

Duas vezes viúvo, onde é que há de ir-se agora, que há de fazer Orfeu? Pranteia, clama, implora, e todo o inferno é surdo, e nenhum deus o atende!

Ao traduzir, por exemplo, “onde é que há de ir-se agora?” [e não, talvez, um mais nuançado "onde é que havia de ir-se então?"], o poeta luso parece-nos pôr o quadro sob o foco de um observador externo que, sobretudo, indaga a si mesmo, sem tanto imiscuir-se na mente do outro amalgamando-se com ele... ${ }^{36} \mathrm{O}$ que se vê na sequência, porém, encontrase de todo inserido num âmbito descritivo, pois ele, apenas, apresenta ao leitor a sucessão dos gestos desesperados de Orfeu após perder Eurídice por força da própria paixão e o infrutífero desenrolar dos mesmos. Em contrapartida, lembremos, todo o par original em Virgílio (versos 504505) correspondia a três perguntas que seria sempre temerário imputar só a Orfeu ou só a Proteu, o narrador.

Ei-nos, portanto, com esses exemplos, diante de uma amostragem dos procedimentos tradutórios do Visconde Antônio Feliciano de Castilho ao verter do latim este antológico relato. Julgamos menos importante, contudo, continuamente "medir" se houve perdas ou ganhos estilísticos no cotejo com os versos originais do que constatar, na média, o deliberado esforço do tradutor para elaborar à sua maneira o texto na língua de chegada. Ciente, imaginamos, de que então dava curso a algo novo, o poeta logrou ao menos fazer as escolhas que lhe pareceram corretas para dotá-lo das características cabíveis numa tradução artística.

${ }^{36}$ Cf. supra nota 24. 


\section{Bibliografia}

AUERBACH, Erich. Mimesis. A representação da realidade na literatura ocidental. São Paulo: Perspectiva, 2002.

BAUDELAIRE, Charles. Flores das "Flores do mal" de Baudelaire. Trad. Guilherme de Almeida. Rio de Janeiro: Ediouro, [s.d.].

CATULO. O livro de Catulo. Tradução, introdução e notas de João Angelo Oliva Neto. São Paulo: Edusp, 1996.

GOLDSTEIN, Norma. Versos, sons, ritmos. São Paulo: Ática, 1986.

HEINZE, Richard. Virgil's epic technique. Translated from the German by Hazel and David Harvey and Fred Robertson. London: Bristol Classical, 2004.

LATINO COELHO, J. M. Garrett e Castilho. Estudos biográficos. Lisboa: Santos \& Vieira, 1917.

LEGRAND, Ph.-E. La poésie aléxandrine. Paris: Payot, 1924.

LODGE, David. A forma na ficção. Guia de métodos analiticos e terminologia. Trad. Maria Angela Aguiar. Porto Alegre: Curso de pós-graduação em Letras da Pontifícia Universidade Católica do Rio Grande do Sul, 1996.

O'HARA, James. Virgil's style. In: MARTINDALE, Charles (Org.). The Cambridge companion to Virgil. Cambridge: University Press, 1997. p. 241-258.

OTIS, Brooks. Virgil: a study in civilized poetry. Norman: Oklahoma University Press, 1995.

RODRIGUES LAPA, Manuel. Estilistica da língua portuguesa. 7. ed. Rio de Janeiro: Livraria Acadêmica, 1973.

TREVIZAM, Matheus. Camena entre Brasil e Portugal. Belo Horizonte: Setor de Publicações da FALE-UFMG, 2008.

VIRGÍLIO. Geórgicas. Eneida. Respectivas traduções de Antônio Feliciano de Castilho e Odorico Mendes; prefácio de Nelson Romero. Rio de Janeiro: W. M. Jackson, 1949.

WILKINSON, Lancelot Patrick. The "Georgics" of Virgil. A critical survey. Norman: Oklahoma University Press, 1997. 


\section{Resumo}

O crítico norte-americano Brooks Otis propôs, em seu estudo Virgil: a study in civilized poetry, a distinção entre "estilo objetivo" e "estilo subjetivo" nas obras do poeta romano. No primeiro caso, os traços empregado na composição privilegiam a fria tessitura da narrativa, enquanto, no segundo, ocorreria o envolvimento afetivo do narrador com o dito. Para Otis, o relato do mito de Orfeu, segundo se faz em Geórgicas IV 453-527, exemplifica o "estilo subjetivo", com a "comoção" do narrador diante da dupla morte de Eurídice e da loucura e morte do próprio Orfeu. Assim, após a apresentação ilustrada desse instrumental analítico, comparamos com Virgílio certos pontos da tradução oitocentista do mito de Orfeu pelo Visconde Antônio Feliciano de Castilho, numa tentativa de verificar o grau de recuperação do estilo do original latino no poema traduzido.

\section{Résumé}

Le critique américain Brooks Otis a proposé, dans son ouvrage Virgil: a study in civilized poetry, la différentiation entre "style objectif" et "style subjectif" à l'oeuvre du poète romain. Dans le premier cas, les traits employés à la composition privilégient le "froid" tissage du récit, tandis que, dans le deuxième, il y aurait l'engagement affectif entre le narrateur et ce qu'il dit. Pour Otis, le récit du mythe d'Orphée, tel qu'on le fait aux Géorgiques IV 453-527, exemplifie le "style subjectif", avec la "commotion" du narrateur en face de la double mort d'Euridice et en face de la folie et mort d'Orphée même. Alors, après la presentation illustrée de cet instrumental analythique, nous comparons avec Virgile certaines parties de la traduction du 19ème. siècle du mythe d'Orphée par le Vicomt Antônio Feliciano de Castilho, en essayant de vérifier l'extention de la récuperation du style de l'original latin dans le poème traduit. 